\title{
Adsorption sites of individual metal atoms on ultrathin $\operatorname{MgO}(100)$ films
}

\author{
Edgar Fernandes, ${ }^{1}$ Fabio Donati, ${ }^{1}$ François Patthey, ${ }^{1}$ Srdjan Stavrić, ${ }^{2}$ Željko Šljivančanin, ${ }^{2,3}$ and Harald Brune ${ }^{1, *}$ \\ ${ }^{1}$ Institute of Physics, Ecole Polytechnique Fédérale de Lausanne, Station 3, CH-1015 Lausanne, Switzerland \\ ${ }^{2}$ Vinča Institute of Nuclear Sciences (020), University of Belgrade, P.O.Box 522, 11001 Belgrade, Serbia \\ ${ }^{3}$ The Science Program, Texas A\&M University at Qatar, Doha, Qatar
}

(Received 10 January 2017; revised manuscript received 28 March 2017; published 17 July 2017)

\begin{abstract}
We use Ca doping during growth of one- and two-monolayer-thick $\mathrm{MgO}$ films on $\mathrm{Ag}(100)$ to identify the adsorption sites of individual adatoms with scanning tunneling microscopy. For this we combine atomic resolution images of the bare $\mathrm{MgO}$ layer with images of the adsorbates and the substitutional $\mathrm{Ca}$ atoms taken at larger tip-sample distance. For Ho atoms, the adsorption sites depend on $\mathrm{MgO}$ thickness. On the monolayer, they are distributed on the $\mathrm{O}$ and bridge sites according to the abundance of those sites, $1 / 3$ and $2 / 3$, respectively. On the $\mathrm{MgO}$ bilayer, $\mathrm{Ho}$ atoms populate almost exclusively the $\mathrm{O}$ site. A third species adsorbed on $\mathrm{Mg}$ is predicted by density functional theory and can be created by atomic manipulation. Au atoms adsorb on the bridge sites for both $\mathrm{MgO}$ thicknesses, while $\mathrm{Co}$ and $\mathrm{Fe}$ atoms prefer the $\mathrm{O}$ sites, again for both thicknesses.
\end{abstract}

DOI: 10.1103/PhysRevB.96.045419

\section{INTRODUCTION}

Single atoms on ultrathin insulating layers grown on metal surfaces have spectacular magnetic properties [1-3], in particular very long spin coherence [4] and even longer spin-relaxation times [5-7], making single-adatom qubits and memories feasible. Moreover, they exhibit multiple stable charge states [8-10]; when adsorbed in the vicinity of defects, they may catalyze chemical reactions [11]. Additionally, on surfaces of bulk oxides they are astonishingly stable [12] and are currently considered as single-atom catalysts [13-15]. These remarkable properties emerge from the interaction of the atom with the surface depending critically on the adsorption site. Knowing this site is therefore mandatory to understand the thermal stability, catalytic properties, charge state, and, finally, the symmetry of the crystal field that determines the lifetime of magnetic quantum states [16].

Field ion microscopy reveals the adsorption site but is limited to strongly bound species on metal surfaces [17]. Scanning tunneling microscopy (STM) and atomic force microscopy (AFM) are more versatile and are now widely employed to determine the adsorption sites of adatoms. However, all examples in the literature are limited to singleelement surfaces [18-21]. On the surfaces of ionic crystals or thin films, such as $\mathrm{MgO}$ or $\mathrm{NaCl}$, one often ignores which of the two sublattices gives rise to the atomic STM and AFM contrast. Density functional theory (DFT) calculations report contradicting results about the STM contrast on $\mathrm{MgO} / \mathrm{Ag}(100)$ [22-24], while AFM contrast of $\mathrm{NaCl}$ was interpreted based on molecular markers for which the adsorption geometry was obtained from DFT [25,26]. Specific to STM, the tunnel parameters required for atomic resolution on insulating layers imply very small tip-sample distances. Under these conditions, adsorbed atoms are frequently displaced or even desorbed, which further complicates the determination of their adsorption site. For example, light adsorbates such as $\mathrm{H}$ can get displaced by tip-sample interactions even under moderate tunnel conditions, yielding fictitious adsorption sites [27]. As an alternative approach, electron paramagnetic resonance

\footnotetext{
*Corresponding author: harald.brune@epfl.ch
}

(EPR) was used to indirectly identify the adsorption site of $\mathrm{Au}$ on thick $\mathrm{MgO}$ layers [28]. However, for the same atoms on three monolayers of $\mathrm{MgO}$ on $\mathrm{Ag}(100)$, the adsorption site is still debated [29-31]. These issues are general for any single atom on the surfaces of ionic crystals or thin films and call for a direct and reliable experimental method.

Here we introduce dilute $\mathrm{Ca}$ doping to mark the $\mathrm{Mg}$ sublattice in STM images of one- and two-monolayer-thick $\mathrm{MgO}$ films grown on $\mathrm{Ag}(100)$. To determine the orientation and size of the atomic $\mathrm{MgO}$ lattice, we record atomic resolution images on adsorbate-free areas. This lattice is overlaid onto STM images of the $\mathrm{Ca}$ dopants and adsorbates taken at larger tip-sample distance. On this grid all $\mathrm{Ca}$ atoms are on identical sites, demonstrating the reliability of our method to mark the Mg positions. A comparison of the adsorbates' positions with this $\mathrm{MgO}$ grid unequivocally identifies the adsorption sites of $\mathrm{Ho}, \mathrm{Au}, \mathrm{Co}$, and $\mathrm{Fe}$ adatoms as a function of $\mathrm{MgO}$ thickness. These four elements are motivated by Ho being the first single-atom magnet [5], the adsorption sites of $\mathrm{Au}$ being debated [29-31], Co having the highest possible magnetocrystalline anisotropy for a $3 d$ element [3], and, finally, $\mathrm{Fe}$ on $\mathrm{MgO}$ being the first system where electron spin resonance (ESR) with the STM was demonstrated [4] and where spin-coherence times were measured on a single atom. DFT calculations reveal the charge transfer and binding energy of the adsorbates on mono- and bilayer $\mathrm{MgO} / \mathrm{Ag}(100)$, as well as on the (100) surface of bulk MgO.

We start by giving details of the experiment and of the DFT calculations in Sec. II. The results and discussion section is divided into five parts. Section III A focuses on the characterization of the pristine and $\mathrm{Ca}$-doped $\mathrm{MgO}$ thin films. Sections III B and III C describe the experimental determination of the adsorption sites of Ho, as well as STM atomic manipulation experiment with these atoms. Sections III D and III E present results on the adsorption site of $\mathrm{Co}, \mathrm{Fe}$, and Au. Section IV concludes the paper.

\section{TECHNICAL DETAILS}

\section{A. Experiment}

The $\operatorname{Ag}(100)$ surface was prepared in ultrahigh vacuum by repeated cycles of $\mathrm{Ar}^{+}$sputtering $\left(800 \mathrm{eV}, 10 \mu \mathrm{A} / \mathrm{cm}^{2}\right)$ and 
subsequent annealing to $770 \mathrm{~K}$. $\mathrm{MgO}$ thin films were grown by evaporating $\mathrm{Mg}$ from a Knudsen cell under a partial pressure of oxygen of $1 \times 10^{-6}$ mbar and with the sample kept at $770 \mathrm{~K}$, as described in Ref. [32]. These conditions yield an $\mathrm{MgO}$ growth rate of about 0.1 monolayer per minute. We define one monolayer (ML) as one $\mathrm{MgO}(100)$ unit cell per $\mathrm{Ag}(100)$ substrate atom. Calcium-doped $\mathrm{MgO}$ films were prepared by coevaporating $\mathrm{Ca}$ and $\mathrm{Mg}$ under the conditions described above and with a Ca flux significantly lower than the $\mathrm{Mg}$ flux, adjusted to obtain the desired dopant concentration. Ho, Co, $\mathrm{Fe}$, and $\mathrm{Au}$ atoms were evaporated from $e$-beam evaporators onto the sample in the STM at $T_{\text {dep }} \approx 10 \mathrm{~K}$ and with a base pressure below $1 \times 10^{-10}$ mbar. STM measurements were performed with a home-built STM at $T_{\mathrm{STM}}=4.7 \mathrm{~K}$ using $\mathrm{W}$ or PtIr tips [33]. Differential conductance $(d I / d V)$ spectra were acquired with a lock-in amplifier using a bias modulation at $1397 \mathrm{~Hz}$ and working with the feedback loop closed to minimize the tip-surface interaction at large biases.

\section{B. Density functional theory calculations}

The DFT calculations for Ho adatoms on $\mathrm{MgO}(100) / \operatorname{Ag}(100)$ were carried out using the WIEN2K computer code [34], with the same computational setup as the one described in Ref. [5], i.e., using the generalized gradient approximation (GGA) and on-site Coulomb interactions. DFT calculations of the $\mathrm{Co}$ and $\mathrm{Au}$ adatoms on thin $\mathrm{MgO}(100)$ films on $\mathrm{Ag}(100)$ were performed with the GPAW code [35], based on the real-space grid implementation of the projector augmented wave (PAW) method [36,37]. Exchange-correlation effects were described employing the Perdew-Burke-Ernzerhof functional (PBE) [38]. For Co, the calculations were performed within the GGA $+U$ approach $[39,40]$, which combines the standard PBE exchange-correlation functional with on-site Coulomb interaction, using a $U$ value of $2 \mathrm{eV}$. The $\mathrm{MgO}(100) / \mathrm{Ag}(100)$ surface was modeled with a $3 \times 3$ unit cell containing nine $\mathrm{Mg}$ and nine $\mathrm{O}$ atoms per $\mathrm{MgO}(100)$ layer, placed on a three-layer metal slab with nine Ag atoms per fcc(100) layer. In all calculations we used theoretically optimized Ag lattice constants of $4.14 \AA$, grid spacing of $0.15 \AA$, two-dimensional periodic boundary conditions parallel to the (100) surfaces, and 16 Monkhorst-Pack k points for sampling the Brillouin zone [41]. Open boundary conditions are applied perpendicular to the surface with $7 \AA$ of vacuum separating the oxide/metal slabs from the cell boundaries. To increase numerical stability of the calculations, the electronic states were occupied according to the Fermi-Dirac distribution with a broadening of $0.1 \mathrm{eV}$. Atomic positions were relaxed using the Broyden-Fletcher-Goldfarb-Shanno algorithm [42].

\section{RESULTS AND DISCUSSION}

\section{A. STM characterization of pristine and Ca-doped MgO thin films}

Figure 1(a) shows an STM image of the $\mathrm{MgO} / \mathrm{Ag}(100)$ surface with the bare substrate coexisting with $\mathrm{MgO}$ layers of two thicknesses. Since their apparent heights are strongly bias dependent and sometimes inverted with respect to the expectation from morphology [43], we use the energies of

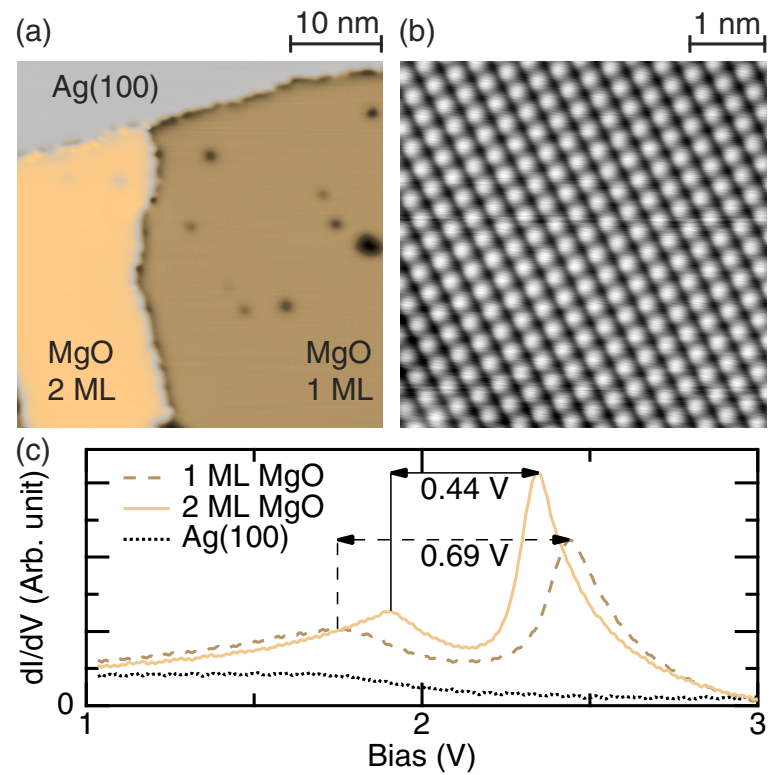

FIG. 1. (a) STM image of $\mathrm{Ag}(100)$ partially covered by $\mathrm{MgO}$ $\left(V_{\mathrm{t}}=0.12 \mathrm{~V}, I_{\mathrm{t}}=100 \mathrm{pA}\right)$. Dark spots are attributed to point defects in the oxide at the interface. (b) Atomically resolved image of 2-ML $\mathrm{MgO}\left(V_{\mathrm{t}}=-10 \mathrm{mV}, I_{\mathrm{t}}=10 \mathrm{nA}\right)$. (c) Field emission resonance spectra recorded above 1- and 2-ML $\mathrm{MgO}$ as well as clean $\mathrm{Ag}(100)$ $\left(V_{\mathrm{t}}=0.12 \mathrm{~V}, I_{\mathrm{t}}=100 \mathrm{pA}\right.$, peak-to-peak modulation amplitude $V_{\text {mod }}=10 \mathrm{mV}$ ).

field emission resonances to determine the $\mathrm{MgO}$ thickness [44]. The $d I / d V$ spectra in Fig. 1(c) exhibit two resonances with distinct energy separations of $0.69 \mathrm{~V}$ and $0.44 \mathrm{~V}$; the first is characteristic of the $\mathrm{MgO}$ monolayer, and the second of the bilayer [44]. Note that a very recent paper [6] proposed an $\mathrm{MgO}$ thickness calibration that differs by one layer from the one used in the current literature and also in the present study. Our method to determine the adsorption sites is independent of the $\mathrm{MgO}$ thickness calibration used, only in the comparison of the experiment with DFT the MgO thickness does play a role.

The atomically resolved STM image of 2-ML $\mathrm{MgO}$ of Fig. 1(b) shows a square lattice of protrusions representing one ionic sublattice [29,44]. The period of $2.90 \pm 0.03 \AA$ agrees very well with the $\mathrm{Ag}(100)$ nearest-neighbor distance of $2.89 \AA$. In addition, the STM image shows no superstructure, such as moiré patterns or dislocations. Both observations provide direct evidence of the $\mathrm{MgO}(100)$ film being uniformly and compressively strained by $3 \%$ to form a pseudomorphic $(1 \times 1)$ structure on $\mathrm{Ag}(100)$. This confirms early diffraction studies [45] that revealed that this lateral compression leads to a vertical expansion of the unit cell by $3.6 \%$ [46]. Whether the protrusions in this image represent the $\mathrm{Mg}$ or the $\mathrm{O}$ species has been a matter of debate in theory [22-24]. Our Ca-doping method introduced hereafter determines it unequivocally for the respective STM tip and tunnel parameters.

Figure 2 shows an overview image of 1- and 2-ML Cadoped $\mathrm{MgO}$. For the employed tunnel parameters, $\mathrm{Ca}$ atoms are imaged as small protrusions with apparent heights of $73 \pm 2 \mathrm{pm}$ and $61 \pm 2 \mathrm{pm}$, respectively, on 1- and 2-ML MgO. The extremely narrow apparent height distribution found for 


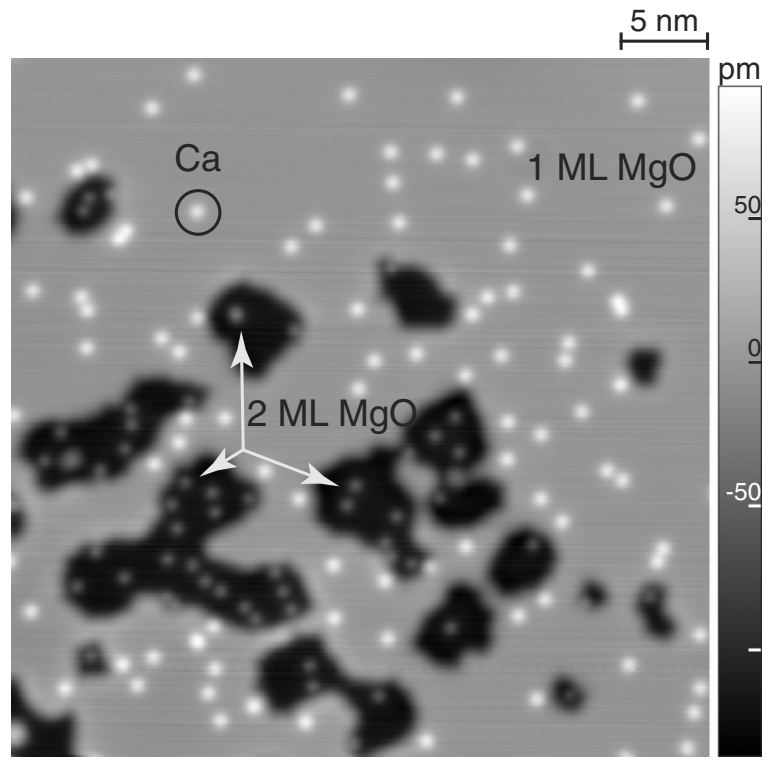

FIG. 2. STM image of one and two monolayers of $\mathrm{MgO}$ with the substitutional $\mathrm{Ca}$ atoms appearing as protrusions $\left(V_{\mathrm{t}}=-515 \mathrm{mV}\right.$, $I_{\mathrm{t}}=100 \mathrm{pA}$ ). Note that the apparent height of the $\mathrm{MgO}$ layers is inverted with respect to their thickness.

each of the two $\mathrm{MgO}$ thicknesses indicates that all $\mathrm{Ca}$ atoms are on identical lattice sites (uncertainties are calculated from the standard deviation of the object's apparent height, i.e., 88 and 50 objects, respectively, on 1- and 2-ML MgO). In addition, the very similar apparent heights observed on 1- and 2-ML MgO suggest that all $\mathrm{Ca}$ atoms are localized in the topmost $\mathrm{MgO}$ layer. $\mathrm{Ca}$ atoms buried in the second layer would appear with a different apparent height and would be located on the other lattice site. Therefore, $\mathrm{Ca}$ protrusions always mark the $\mathrm{Mg}$ lattice positions of the topmost layer irrespective of the local $\mathrm{MgO}$ thickness. Our conclusion of $\mathrm{Ca}$ surface segregation is supported by the literature [47-49]. Upon annealing of Ca-rich $\mathrm{MgO}$ crystals, $\mathrm{Mg}$ atoms at the surface are replaced with $\mathrm{Ca}$. For our employed $\mathrm{Ca}$ doping of the order of $0.5 \%$ practically all the $\mathrm{Ca}$ atoms are sufficiently far from each other to appear as individual and identical protrusions (see Figs. 2 and 4).

\section{B. Adsorption sites determination of Ho adatoms on thin $\mathrm{MgO}$ films}

Figures 3(a) and 3(b) show $5 \times 10^{-3}$ ML of Ho deposited at $10 \mathrm{~K}$ on 1- and 2-ML of $\mathrm{MgO} / \mathrm{Ag}(100)$. While two species with characteristic apparent heights coexist on 1-ML MgO, on 2-ML the species with smaller apparent height $\left(\mathrm{Ho}^{\mathrm{A}}\right)$ occurs almost exclusively.

Figure 4 shows a single $\mathrm{MgO}$ layer with substitutional $\mathrm{Ca}$ atoms, as well as both adsorbed Ho species. Calcium atoms appear as faint spots with an apparent height of $67 \pm 12 \mathrm{pm}$ for this tunneling set-point. Note that the higher uncertainty stems from the standard deviation obtained from the five $\mathrm{Ca}$ protrusions. The tunneling conditions yielding atomic resolution on $\mathrm{MgO}$ move the $\mathrm{Ho}$ atoms, and therefore, we imaged a bare $\mathrm{MgO}$ spot of the same sample with atomic resolution and extracted the orientation and lattice constant of the $\mathrm{MgO}$ lattice from it. This lattice was then overlaid onto Fig. 4, and one of its $\mathrm{Mg}$ atoms was aligned with one of
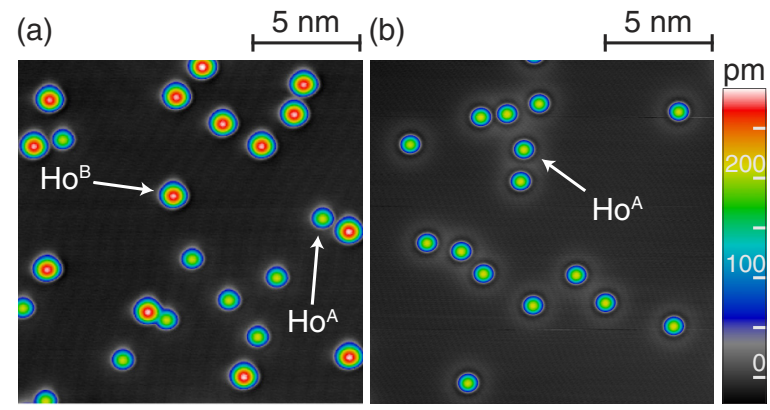

FIG. 3. STM images of (a) 1-ML and (b) 2-ML undoped $\mathrm{MgO}$ after the adsorption of $5 \times 10^{-3} \mathrm{ML}$ of Ho. Two species, $\mathrm{Ho}^{\mathrm{A}}$ and $\mathrm{Ho}^{\mathrm{B}}$, are discerned by their apparent heights of $220 \pm 4 \mathrm{pm}$ and $295 \pm 3 \mathrm{pm}$, respectively $\left(T_{\mathrm{dep}} \approx 10 \mathrm{~K}, V_{\mathrm{t}}=-20 \mathrm{mV}, I_{\mathrm{t}}=20 \mathrm{pA}\right)$.

the substitutional $\mathrm{Ca}$ atoms. All other $\mathrm{Ca}$ species fall exactly onto $\mathrm{Mg}$ sites, illustrating the precision of the alignment. This technique has been applied on images up to $20 \times 20 \mathrm{~nm}^{2}$ containing up to $12 \mathrm{Ca}$ atoms (not shown here) with the same reliability. Comparing the Ho positions with the overlaid $\mathrm{MgO}$ lattice for the shown image and for many additional ones, we infer that $\mathrm{Ho}^{\mathrm{A}}$ adsorbs on $\mathrm{O}$ while $\mathrm{Ho}^{\mathrm{B}}$ is on a bridge site. Thus, the preferred adsorption site on two $\mathrm{MgO}$ layers is on top of oxygen. In agreement, our DFT calculations identify this site for $2-\mathrm{ML} \mathrm{MgO} / \mathrm{Ag}(100)$ as the most stable one (see Table I). They also show that this site is favored for $\mathrm{MgO}(100)$ bulk. Therefore, from 2-ML $\mathrm{MgO}$ on, the ensemble of Ho atoms is dominated by a single species. This facilitates the interpretation of ensemble measurements, such as x-ray magnetic circular dichroism [5].

The very different abundances of both Ho species on 1- and 2-ML $\mathrm{MgO}$ can be traced back to MgO thicknessdependent dissipation of the adsorption energy. On 1-ML

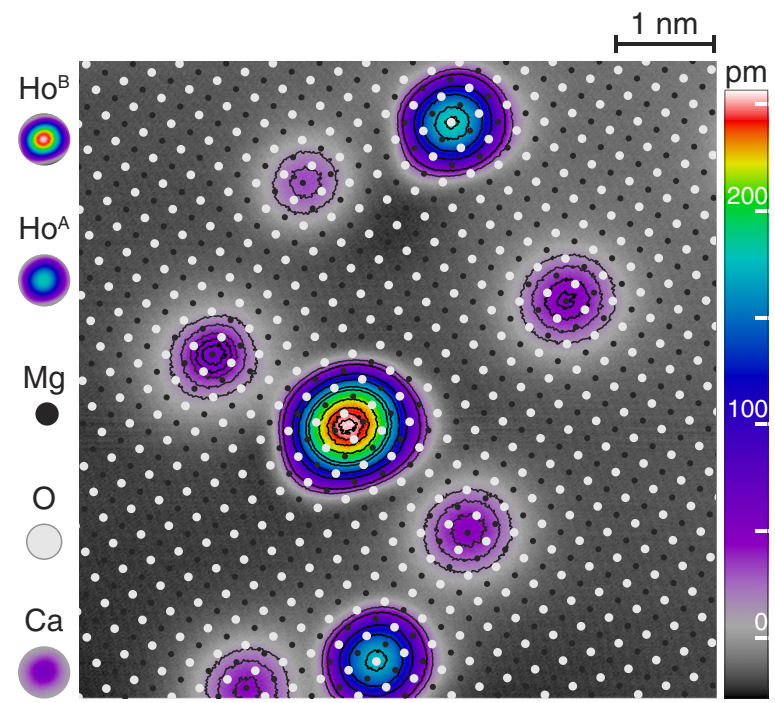

FIG. 4. STM image of 1 -ML $\mathrm{MgO}$ grown with $5 \times 10^{-3} \mathrm{ML} \mathrm{Ca}$ doping and the same number density of Ho atoms adsorbed onto it. The orientation and spacing of the overlaid $\mathrm{MgO}$ lattice were determined from an atomically resolved image recorded on a bare $\mathrm{MgO}$ spot of the same sample. This lattice was then translated to bring one of its $\mathrm{Mg}$ atoms in coincidence with one of the Ca species $\left(V_{\mathrm{t}}=-20 \mathrm{mV}, I_{\mathrm{t}}=20 \mathrm{pA}\right)$. 
TABLE I. DFT binding-energy differences $\Delta E(\mathrm{eV})$ and charge transfers $\Delta q(e)$ for individual $\mathrm{Ho}, \mathrm{Au}$, and $\mathrm{Co}$ atoms on $\mathrm{O}$, bridge (br), and $\mathrm{Mg}$ sites on 1- and 2-ML-thick $\mathrm{MgO} / \mathrm{Ag}(100)$ and on the (100) surface of $\mathrm{MgO}$ bulk. The site with the highest binding energy is taken as the reference; positive values signify a decrease in binding energy.

\begin{tabular}{|c|c|c|c|c|c|c|c|}
\hline \multirow[b]{2}{*}{ Atom } & \multirow[b]{2}{*}{ Site } & \multicolumn{2}{|c|}{ 1-ML MgO/Ag } & \multicolumn{2}{|c|}{ 2-ML $\mathrm{MgO} / \mathrm{Ag}$} & \multicolumn{2}{|c|}{$\mathrm{MgO}(100)$} \\
\hline & & $\Delta E$ & $\Delta q$ & $\Delta E$ & $\Delta q$ & $\Delta E$ & $\Delta q$ \\
\hline \multirow[t]{3}{*}{ Но } & $\mathrm{O}$ & 0.90 & 0.26 & 0.00 & 0.12 & 0.00 & -0.06 \\
\hline & br & 0.33 & 0.56 & 0.19 & 0.71 & 0.61 & -0.42 \\
\hline & $\mathrm{Mg}$ & 0.00 & 1.20 & 0.21 & 1.21 & & \\
\hline \multirow[t]{3}{*}{$\mathrm{Au}$} & $\mathrm{O}$ & 0.04 & -0.77 & 0.18 & -0.80 & 0.00 & -0.28 \\
\hline & br & 0.00 & -0.77 & 0.00 & -0.83 & 0.15 & -0.31 \\
\hline & $\mathrm{Mg}$ & 0.19 & -0.73 & 0.18 & -0.79 & 0.35 & -0.26 \\
\hline \multirow[t]{3}{*}{$\mathrm{Co}$} & $\mathrm{O}$ & 0.00 & 0.14 & 0.00 & 0.01 & 0.00 & -0.13 \\
\hline & br & 0.09 & 0.52 & 0.12 & 0.45 & 0.29 & -0.09 \\
\hline & $\mathrm{Mg}$ & 0.52 & 0.92 & & & & \\
\hline
\end{tabular}

$\mathrm{MgO}$, the abundance of both species $\left(\mathrm{Ho}^{\mathrm{A}}: 35.8 \% \pm 1.6 \%\right.$, $\mathrm{Ho}^{\mathrm{B}}: 64.2 \% \pm 1.6 \%$ ) reflects that of their adsorption sites since there are two times more bridge than $\mathrm{O}$ sites. This is compatible to statistical growth, where the atoms come to rest at their site of impact, irrespective of its adsorption energy. The clear preference of the $\mathrm{O}$ site for $2-\mathrm{ML} \mathrm{MgO}\left(\mathrm{Ho}^{\mathrm{A}}: 91.5 \% \pm 1.7 \%\right.$, $\mathrm{Ho}^{\mathrm{B}}: 8.5 \% \pm 1.7 \%$ ) implies adatom motion. Thermal mobility can be ruled out since both species are immobile for hours up to $50 \mathrm{~K}$. Therefore, the Ho atoms exhibit transient mobility, at least from the bridge toward the adjacent $\mathrm{O}$ site [50]. The fact that this occurs more readily on 2-ML MgO than on 1-ML $\mathrm{MgO}$ is related to the dissipation of the adsorption energy via electron-hole pair excitation in the substrate [51,52], which is more efficient for atoms adsorbing on thinner $\mathrm{MgO}$ layers.

\section{STM manipulation of Ho adsorption sites}

On 1-ML $\mathrm{MgO} / \mathrm{Ag}(100)$, the DFT calculations identify the $\mathrm{Mg}$ site as the most favorable one for Ho atoms. Although Ho atoms do not spontaneously reach this site after deposition, we can populate it by atomic manipulation. For this we apply voltage ramps with the STM tip placed above the Ho atoms. To prevent major modifications of the probed area by high electric fields, the voltage is ramped while keeping the feedback loop closed; that is, the tunneling current stays constant while the tip retracts smoothly. Abrupt changes in the vertical position of the tip detected during the ramp evince a modification or a displacement of the probed atom [8]. Figures 5(a)-5(c) illustrate the result of this process on a few selected Ho atoms on 1-ML MgO. Ramping the bias up to $-1 \mathrm{~V}$ on the $\mathrm{Ho}^{\mathrm{A}}$ atoms [Fig. 5(a)] switches them to $\mathrm{Ho}^{\mathrm{B}}$. As a result, in Fig. 5(b) all the atoms have the same apparent height and are adsorbed on the bridge site. We note that this operation is reversible; that is, positive-bias ramping up to $+1 \mathrm{~V}$ on top of a $\mathrm{Ho}^{\mathrm{B}}$ transforms it back into $\mathrm{Ho}^{\mathrm{A}}$. Conversely, further ramping with negative biases up to $-1.2 \mathrm{~V}$ on top of $\mathrm{Ho}^{\mathrm{B}}$ atoms irreversibly switches them to a new species, $\mathrm{Ho}^{\mathrm{C}}$ [see Fig. 5(c)]. With an apparent height of $141 \pm 3 \mathrm{pm}$, this species appears much smaller than $\mathrm{Ho}^{\mathrm{A}}$ or $\mathrm{Ho}^{\mathrm{B}}$. Similar atomic manipulations yield an equivalent

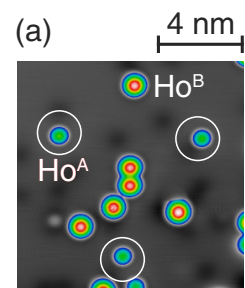

(d)

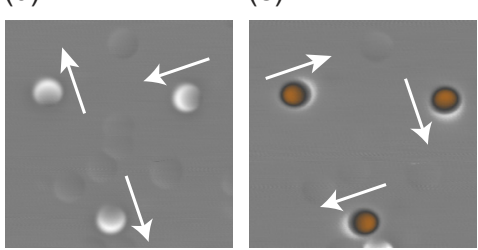

FIG. 5. STM images of Ho atoms on 1-ML MgO. Atoms indicated with circles are successively transformed from (a) $\mathrm{Ho}^{\mathrm{A}}$ to (b) $\mathrm{Ho}^{\mathrm{B}}$ and finally to (c) $\mathrm{Ho}^{\mathrm{C}}$ by applying negative voltage ramps; see text for details [in (a)-(c), $V_{\mathrm{t}}=-100 \mathrm{mV}, I_{\mathrm{t}}=20 \mathrm{pA}$ ]. (d) Subtraction of image (a) from (b) using the unchanged atoms for precise alignment. (e) Subtraction of (b) from (c). White (brown) indicates levels above (below) the zero plane. Arrows indicate the directions of the atomic displacements.

sequence of adsorption sites also on two MgO layers. Using the unchanged atoms as reference, we identify the possible displacement of the switched adatoms by subtracting subsequent images. Figure 5(d), obtained by subtracting Fig. 5(a) from Fig. 5(b), shows asymmetric spots at the positions of the three circled atoms. The white arrows point in the direction of the displacement and indicate that the switched atoms have moved along two perpendicular directions, which correspond to the two possibilities of hopping from an $\mathrm{O}$ to a bridge site. By subtracting Fig. 5(b) from Fig. 5(c), we observe that the switched atoms have been displaced perpendicular to their
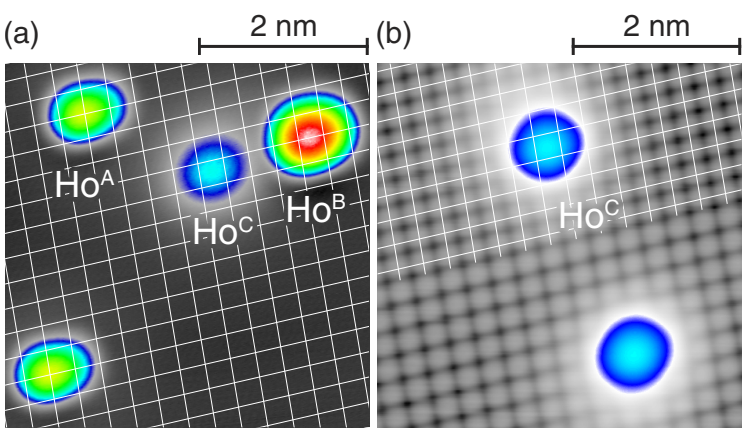

FIG. 6. (a) STM image of all three Ho species on 1-ML $\mathrm{MgO}\left(V_{\mathrm{t}}=-20 \mathrm{mV}, I_{\mathrm{t}}=20 \mathrm{pA}\right) . \mathrm{Ho}^{\mathrm{C}}$ has an apparent height of $141 \pm 3 \mathrm{pm}$ and is adsorbed on $\mathrm{Mg}$. The lattice is again inferred from an atomically resolved image of the bare $\mathrm{MgO}$ surface and marks the $\mathrm{O}$ atoms of the $\mathrm{MgO}$. (b) Atomically resolved image of two $\mathrm{Ho}^{\mathrm{C}}$ atoms on 2-ML MgO. The lattice marks the $\mathrm{O}$ atoms that appear as protrusions $\left(V_{\mathrm{t}}=-20 \mathrm{mV}, I_{\mathrm{t}}=5 \mathrm{nA}\right.$ ). Note that (b) was recorded using the same tunneling parameters all along the image scan. The grid overlays the atomic protrusions, located at $\mathrm{O}$ lattice positions. Only half of the grid is shown to better distinguish the atomic protrusions in the lower part. 

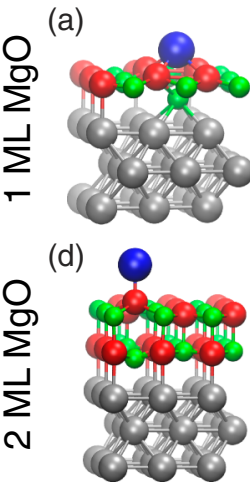

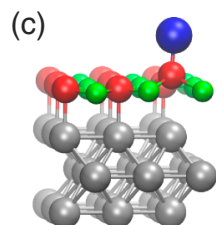

(e)

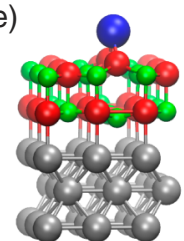

(b)

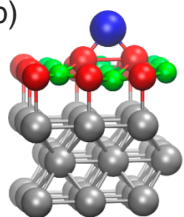

(f)

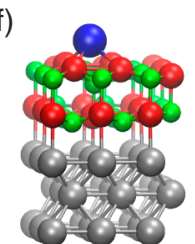

FIG. 7. DFT adsorption geometries of a Ho adatom on (a)-(c) one and (d)-(f) two MgO monolayers in order of decreasing binding energy from left to right. Color legend: red, $\mathrm{O}$; green, $\mathrm{Mg}$; gray, $\mathrm{Ag}$; blue, Ho.

previous direction, i.e., from a bridge to an $\mathrm{Mg}$ site [see Fig. 5(e)].

$\mathrm{Ho}^{\mathrm{C}}$ adatoms are remarkably stable. Voltage ramps up to $\pm 10 \mathrm{~V}$ have no effect on them, while $\mathrm{Ho}^{\mathrm{A}}$ and $\mathrm{Ho}^{\mathrm{B}}$ are transformed or desorbed under these conditions. Figure 6(a) shows the adsorption site of $\mathrm{Ho}^{\mathrm{C}}$ to be on top of $\mathrm{Mg}$. The grid marks the $\mathrm{O}$ sites and was determined with the same method as the one used for Fig. 4.

As shown by our DFT calculations for $1-\mathrm{ML} \mathrm{MgO}$, this extraordinary stability results from a strong relaxation of the surrounding $\mathrm{O}$ neighbors and of the underlying $\mathrm{Mg}$ atom, making this binding site fourfold $\mathrm{O}$ coordinated [see Fig. 7(a)]. In agreement with experiment, this site has the highest binding energy, followed by the bridge and $\mathrm{O}$ sites, whose atomic geometries are shown in Figs. 7(b) and 7(c), respectively. See Table I for the differences in binding energy and charge state of the atoms in the respective sites.

On 2-ML MgO, adsorption on top of $\mathrm{Mg}$ is calculated to be less favorable due to the presence of the subsurface $\mathrm{MgO}$

layer preventing large relaxation of the surface lattice [see Fig. 7(f)]. Nevertheless, experiment still finds this site to be the most stable one, although it is reachable only after atomic manipulation. Note also that the order of the charge states is in agreement with the atomic manipulation from $\mathrm{O}$ via bridge to $\mathrm{Mg}$ sites, requiring increasingly negative voltages. As also observed for $\mathrm{Au}$ and $\mathrm{Ag}$ on $\mathrm{NaCl}(100)$ [8-10], this indicates that the atoms become more and more positively charged along the transformation sequence.

The stability of the $\mathrm{Ho}^{\mathrm{C}}$ species enables imaging it under tunnel conditions that yield atomic resolution on $\mathrm{MgO}$. These conditions displace or desorb Ho atoms adsorbed on the other two sites. The lattice overlaid onto Fig. 6(b) marks the $\mathrm{O}$ atoms that appear as protrusions. According to our experience, this contrast is by far the most common one in low-bias images of the $\mathrm{MgO}$ surface. Only in very rare cases of tip chemistry and tunnel parameters are the Mg atoms imaged as protrusions. This clarifies the controversial DFT results on the STM contrast of $\mathrm{MgO} / \mathrm{Ag}(100)$ [22-24].

\section{Adsorption site of $\mathrm{Co}$ and $\mathrm{Fe}$ on $\mathrm{MgO}$}

Our method of $\mathrm{Ca}$ doping can be applied to determine the adsorption site of any adatom on $\mathrm{MgO}$. Once the site of one species is determined, one can use that species as a marker to identify the sites of other atoms that are coadsorbed. We use Ho atoms as markers for $\mathrm{O}$ and bridge sites to determine the adsorption site of coadsorbed Co adatoms. Figure 8(a) shows a 1-ML-thick $\mathrm{MgO}$ region with coadsorbed Ho and Co atoms. The overlaid grid has again been extracted from atomically resolved images of the substrate and then been brought to coincidence with the $\mathrm{Ho}^{\mathrm{A}}$ atoms. It therefore marks the $\mathrm{O}$ atoms, and one sees that all $\mathrm{Co}$ atoms on that image are adsorbed on top of $\mathrm{O}$, in agreement with Ref. [5]. Notice that $\mathrm{Co}$ is always on $\mathrm{O}$, independent of the $\mathrm{MgO}$ layer thickness (up to three layers), in excellent agreement with DFT. Using (a)

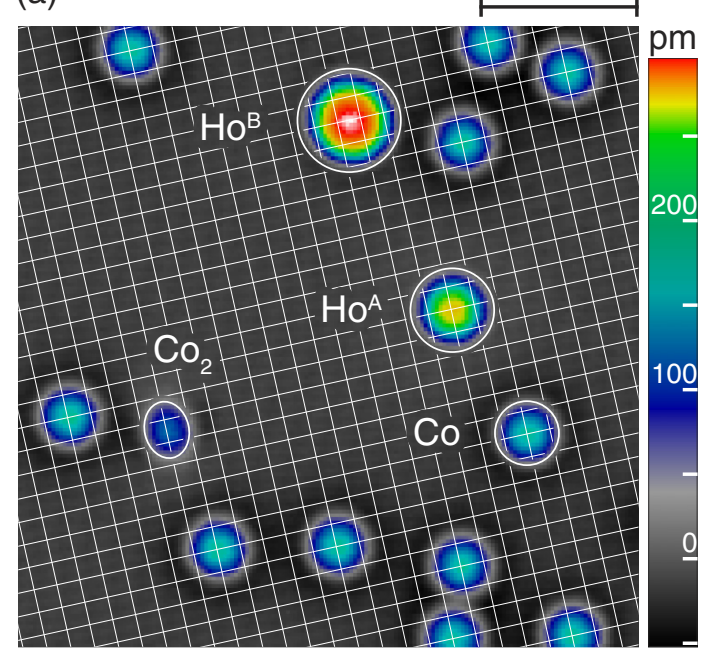

(b)

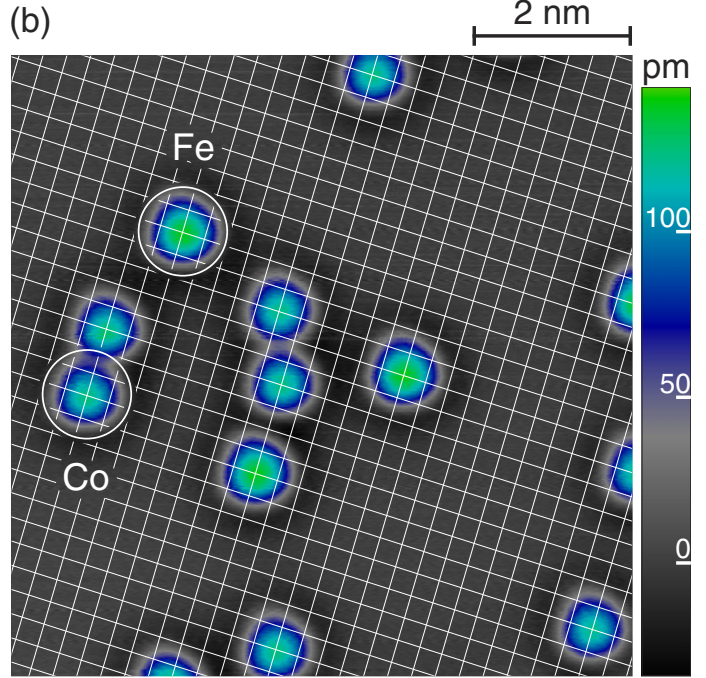

FIG. 8. STM images of (a) coadsorbed Co and $\mathrm{Ho}$ and (b) Co and Fe on 1-ML MgO(100)/ $\mathrm{Ag}(100)$. The lattices are inferred from atomically resolved images of the bare $\mathrm{MgO}$ surface of the respective samples and mark the $\mathrm{O}$ positions. In (a) $V_{\mathrm{t}}=-20 \mathrm{mV}, I_{\mathrm{t}}=20 \mathrm{pA}$, and in (b) $V_{\mathrm{t}}=-50 \mathrm{mV}, I_{\mathrm{t}}=20 \mathrm{pA}$. 
(a)
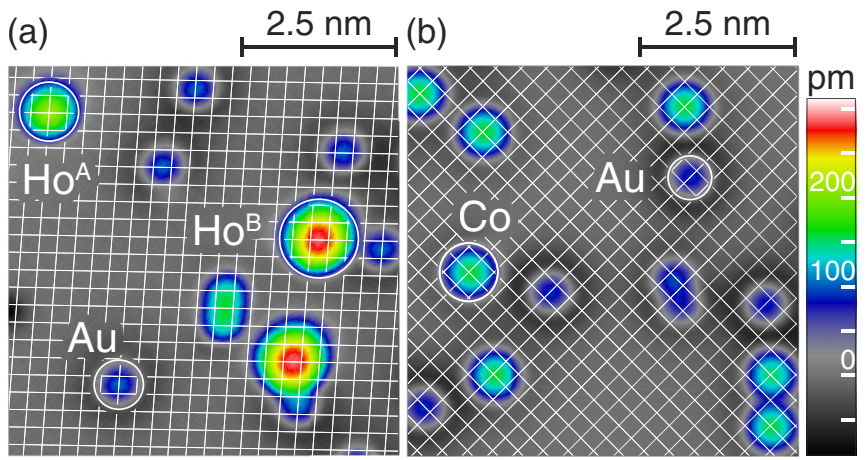

FIG. 9. STM image of coadsorption of (a) Au and Ho and (b) Au and $\mathrm{Co}$ on 1-ML $\mathrm{MgO} / \mathrm{Ag}(100)$. The overlaid lattices mark oxygen positions in both cases. All $\mathrm{Au}$ atoms are found on the bridge site. $V_{\mathrm{t}}=-100 \mathrm{mV}$ and $I_{\mathrm{t}}=20 \mathrm{pA}$ in both STM images.

Co as a marker for the $\mathrm{O}$ sites, we further determine that $\mathrm{Fe}$ also adsorbs on top of O [Fig. 8(b)], confirming previous DFT calculations $[3,5,24,53-56]$. Additionally, we note the presence of an elongated object with an apparent height of $135 \pm 3 \mathrm{pm}$, marked in Fig. 8. Scanning tunneling spectroscopy reveals inelastic steps at around $10 \mathrm{mV}$. Therefore, they are identified as Co dimers [57]. We find that their axis is aligned along the $\mathrm{O}$ sublattice and each of the two constituent atoms is directly above or at least very close to an $\mathrm{O}$ site. This result indicates that our method can be extended to few-atom clusters or small molecules.

\section{E. Adsorption sites of $\mathrm{Au}$ on $\mathrm{MgO}$}

We now apply our method to $\mathrm{Au}$ atoms, for which contradictory results were reported in the literature [29-31]. Figure 9(a) shows 1-ML MgO with coadsorbed $\mathrm{Au}$ and $\mathrm{Ho}$ and a grid with lattice spacing and orientation again extracted from an atomically resolved bare $\mathrm{MgO}$ spot of the same sample. $\mathrm{Ho}^{\mathrm{A}}$ and $\mathrm{Ho}^{\mathrm{B}}$ atoms are used to align the grid such that it represents the O positions. All the Au atoms shown in Fig. 9(a) are on bridge sites. A statistical analysis over $50 \mathrm{Au}$ atoms on 1-ML $\mathrm{MgO}$ indicates that they almost exclusively adsorb on bridge sites, with a small fraction $(8 \% \pm 4 \%)$ found on top of $\mathrm{Mg}$. An equivalent identification done by codepositing $\mathrm{Co}$ and $\mathrm{Au}$ atoms and using the $\mathrm{Co}$ atoms as reference for the $\mathrm{O}$ sublattice provides the same result within the error bars [see Fig. 9(b)]. Table I shows that DFT finds the highest binding energy on the bridge site for mono- and bilayer $\mathrm{MgO}$ and for the $\mathrm{O}$ site on $\mathrm{MgO}$ bulk, the latter supporting former EPR experiments [28] and DFT calculations [31].
The use of adsorbates or substitutional atoms as atomic markers is the key to identifying an adatom's adsorption site on ionic or more general multielement surfaces. STM images of $\mathrm{Au}$ atoms on 3-ML $\mathrm{MgO}$ were interpreted with an atomic lattice that was not calibrated with substitutional doping or other means, and a close to equivalent occupation of $\mathrm{O}$ and $\mathrm{Mg}$ sites was inferred [29]. A small translation of this lattice by half of its lattice parameter would identify the two species as the two differently oriented bridge sites, thus compatible with our present finding and with former DFT calculations for $\mathrm{Au}$ atoms on 1- to 4-ML $\mathrm{MgO} / \mathrm{Mo}(100)$ [30]. On mono- and bilayer $\mathrm{MgO}$ films, the presence of the substrate allows for an effective charge transfer to the adsorbed atom. Conversely, the charge transfer is reduced in the absence of a metal support, as our DFT calculations and Refs. [30,31] show. In addition to the reduced charge transfer to the substrate, DFT predicts a change in the adsorption site from bridge to oxygen going from ultrathin $\mathrm{MgO}$ films on $\mathrm{Ag}(100)$ to $\mathrm{MgO}$ bulk. This result is in agreement with a former EPR experiment, which reported adsorption on top of $\mathrm{O}$ for $20-\mathrm{ML} \mathrm{MgO} / \mathrm{Ag}(100)$ [28]. We therefore infer that the transition between the bridge and the O site occurs for $\mathrm{MgO}$ thickness above $3 \mathrm{ML}$ [29].

\section{CONCLUSION}

We presented a viable way to experimentally determine the adsorption site of adatoms on surfaces made of two or more elements and to interpret atomically resolved STM images thereof. For the specific case of $\mathrm{MgO}$, we determine the adsorption sites of $\mathrm{Ho}, \mathrm{Co}, \mathrm{Fe}$, and $\mathrm{Au}$ for the $\mathrm{MgO}$ monoand bilayers grown on $\operatorname{Ag}(100)$. These results are important for understanding the fascinating electronic, catalytic, and magnetic properties of individual adatoms on thin films of ionic crystals.

\section{ACKNOWLEDGMENTS}

We acknowledge support from the Swiss National Science Foundation under Projects 140479 and 157081, as well as the Serbian Ministry of Education and Science under Grants No. ON171033 and No. ON171017. The DFT calculation were performed both on the PARADOX-IV supercomputer at the Scientific Computing Laboratory (SCL) of the Institute of Physics Belgrade and on the Beskow supercomputer at the Swedish Center for High Performance Computing, available through the PRACE DECI-13 grant.
[1] A. J. Heinrich, J. A. Gupta, C. P. Lutz, and D. M. Eigler, Science 306, 466 (2004).

[2] A. F. Otte, M. Ternes, K. v. Bergmann, S. Loth, H. Brune, C. P. Lutz, C. F. Hirjibehedin, and A. J. Heinrich, Nat. Phys. 4, 847 (2008).

[3] I. G. Rau, S. Baumann, S. Rusponi, F. Donati, S. Stepanow, L. Gragnaniello, J. Dreiser, C. Piamonteze, F. Nolting, S. Gangopadhyay, O. R. Albertini, R. M. Macfarlane, C. P. Lutz,
B. A. Jones, P. Gambardella, A. J. Heinrich, and H. Brune, Science 344, 988 (2014).

[4] S. Baumann, W. Paul, T. Choi, C. P. Lutz, A. Ardavan, and A. J. Heinrich, Science 350, 417 (2015).

[5] F. Donati, S. Rusponi, S. Stepanow, C. Wäckerlin, A. Singha, L. Persichetti, R. Baltic, K. Diller, F. Patthey, E. Fernandes, J. Dreiser, Ž. Šljivančanin, K. Kummer, C. Nistor, P. Gambardella, and H. Brune, Science 352, 318 (2016). 
[6] W. Paul, K. Yang, S. Baumann, N. Romming, T. Choi, C. P. Lutz, and A. J. Heinrich, Nat. Phys. 13, 403 (2017).

[7] F. D. Natterer, K. Yang, W. Paul, P. Willke, T. Choi, T. Greber, A. J. Heinrich, and C. P. Lutz, Nature (London) 543, 226 (2017).

[8] J. Repp, G. Meyer, F. E. Olsson, and M. Persson, Science 305, 493 (2004).

[9] F. E. Olsson, S. Paavilainen, M. Persson, J. Repp, and G. Meyer, Phys. Rev. Lett. 98, 176803 (2007).

[10] W. Steurer, J. Repp, L. Gross, I. Scivetti, M. Persson, and G. Meyer, Phys. Rev. Lett. 114, 036801 (2015).

[11] A. S. Wörz, K. Judai, S. Abbet, J. M. Antonietti, U. Heiz, A. D. Vitto, L. Giordano, and G. Pacchioni, Chem. Phys. Lett. 399, 266 (2004).

[12] Z. Novotný, G. Argentero, Z. Wang, M. Schmid, U. Diebold, and G. S. Parkinson, Phys. Rev. Lett. 108, 216103 (2012).

[13] X. F. Yang, A. Wang, B. Qiao, J. Li, J. Liu, and T. Zhang, Acc. Chem. Res. 46, 1740 (2013).

[14] G. S. Parkinson, Z. Novotny, G. Argentero, M. Schmid, J. Pavelec, R. Kosak, P. Blaha, and U. Diebold, Nat. Mater. 12, 724 (2013).

[15] R. Bliem, J. van der Hoeven, A. Zavodny, O. Gamba, J. Pavelec, P. E. de Jongh, M. Schmid, U. Diebold, and G. S. Parkinson, Angew. Chem., Int. Ed. 54, 13999 (2015).

[16] C. Hübner, B. Baxevanis, A. A. Khajetoorians, and D. Pfannkuche, Phys. Rev. B 90, 155134 (2014).

[17] S. C. Wang and G. Ehrlich, Phys. Rev. Lett. 62, 2297 (1989).

[18] H. Brune, J. Wintterlin, G. Ertl, and R. J. Behm, Europhys. Lett. 13, 123 (1990).

[19] J. Repp, G. Meyer, K. H. Rieder, and P. Hyldgaard, Phys. Rev. Lett. 91, 206102 (2003).

[20] F. Donati, Q. Dubout, G. Autès, F. Patthey, F. Calleja, P. Gambardella, O. V. Yazyev, and H. Brune, Phys. Rev. Lett. 111, 236801 (2013).

[21] T. Eelbo, M. Waśniowska, M. Gyamfi, S. Forti, U. Starke, and R. Wiesendanger, Phys. Rev. B 87, 205443 (2013).

[22] N. Lopez and S. Valeri, Phys. Rev. B 70, 125428 (2004).

[23] A. Malashevich, E. I. Altman, and S. Ismail-Beigi, Phys. Rev. B 90, 165426 (2014).

[24] H. Y. T. Chen and G. Pacchioni, Phys. Chem. Chem. Phys. 16, 21838 (2014).

[25] K. Lämmle, T. Trevethan, A. Schwarz, M. Watkins, A. Shluger, and R. Wiesendanger, Nano Lett. 10, 2965 (2010).

[26] G. Teobaldi, K. Lämmle, T. Trevethan, M. Watkins, A. Schwarz, R. Wiesendanger, and A. L. Shluger, Phys. Rev. Lett. 106, 216102 (2011).

[27] C. Klein, A. Eichler, E. L. D. Hebenstreit, G. Pauer, R. Koller, A. Winkler, M. Schmid, and P. Varga, Phys. Rev. Lett. 90, 176101 (2003).

[28] M. Yulikov, M. Sterrer, M. Heyde, H.-P. Rust, T. Risse, H.-J. Freund, G. Pacchioni, and A. Scagnelli, Phys. Rev. Lett. 96, 146804 (2006).

[29] M. Sterrer, T. Risse, M. Heyde, H.-P. Rust, and H.-J. Freund, Phys. Rev. Lett. 98, 206103 (2007).

[30] K. Honkala and H. Häkkinen, J. Phys. Chem. C 111, 4319 (2007).

[31] G. Pacchioni, L. Giordano, and M. Baistrocchi, Phys. Rev. Lett. 94, 226104 (2005).

[32] J. Pal, M. Smerieri, E. Celasco, L. Savio, L. Vattuone, and M. Rocca, Phys. Rev. Lett. 112, 126102 (2014).
[33] R. Gaisch, J. Gimzewski, B. Reihl, R. Schlittler, M. Tschudy, and W. Schneider, Ultramicroscopy 42, 1621 (1992).

[34] P. Blaha, K. Schwarz, G. Madsen, D. Kvasnicka, and J. Luitz, WIEN2k: An Augmented Plane Wave plus Local Orbitals Program for Calculating Crystal Properties (Karlheinz Schwarz, Techn. Universität Wien, Austria, 2001).

[35] J. Enkovaara, C. Rostgaard, J. J. Mortensen, J. Chen, M. Dułak, L. Ferrighi, J. Gavnholt, C. Glinsvad, V. Haikola, H. A. Hansen, H. H. Kristoffersen, M. Kuisma, A. H. Larsen, L. Lehtovaara, M. Ljungberg, O. Lopez-Acevedo, P. G. Moses, J. Ojanen, T. Olsen, V. Petzold, N. A. Romero, J. Stausholm-Møller, M. Strange, G. A. Tritsaris, M. Vanin, M. Walter, B. Hammer, H. Häkkinen, G. K. H. Madsen, R. M. Nieminen, J. K. Nørskov, M. Puska, T. T. Rantala, J. Schiøtz, K. S. Thygesen, and K. W. Jacobsen, J. Phys. Condens. Matter 22, 253202 (2010).

[36] P. E. Blöchl, Phys. Rev. B 50, 17953 (1994).

[37] J. J. Mortensen, L. B. Hansen, and K. W. Jacobsen, Phys. Rev. B 71, 035109 (2005).

[38] J. P. Perdew, K. Burke, and M. Ernzerhof, Phys. Rev. Lett. 77, 3865 (1996).

[39] V. I. Anisimov, J. Zaanen, and O. K. Andersen, Phys. Rev. B 44, 943 (1991).

[40] S. L. Dudarev, G. A. Botton, S. Y. Savrasov, C. J. Humphreys, and A. P. Sutton, Phys. Rev. B 57, 1505 (1998).

[41] H. J. Monkhorst and J. D. Pack, Phys. Rev. B 13, 5188 (1976).

[42] D. C. Liu and J. Nocedal, Math. Program. 45, 503 (1989).

[43] S. Baumann, I. G. Rau, S. Loth, C. P. Lutz, and A. J. Heinrich, ACS Nano 8, 1739 (2014).

[44] S. Schintke, S. Messerli, M. Pivetta, F. Patthey, L. Libioulle, M. Stengel, A. De Vita, and W.-D. Schneider, Phys. Rev. Lett. 87, 276801 (2001).

[45] J. Wollschläger, J. Viernow, C. Tegenkamp, D. Erdös, K. M. Schröder, and H. Pfnür, Appl. Surf. Sci. 142, 129 (1999).

[46] S. Valeri, S. Altieri, A. d. Bona, P. Luches, C. Giovanardi, and T. S. Moia, Surf. Sci. 507, 311 (2002).

[47] S. Stankic, M. Sterrer, P. Hofmann, J. Bernardi, O. Diwald, and E. Knözinger, Nano Lett. 5, 1889 (2005).

[48] P. W. Tasker, E. Colbourn, and W. MacKrodt, J. Am. Ceram. Soc. 68, 74 (1985).

[49] R. C. McCune and P. Wynblatt, J. Am. Ceram. Soc. 66, 111 (1983).

[50] D. Z. Gao, M. B. Watkins, and A. L. Shluger, J. Phys. Chem. C 116, 14471 (2012).

[51] O. Bünermann, H. Jiang, Y. Dorenkamp, A. Kandratsenka, S. Janke, D. J. Auerbach, and A. M. Wodtke, Science 350, 1346 (2015).

[52] H. Brune, Science 350, 1321 (2015).

[53] A. Markovits, J. C. Paniagua, N. López, C. Minot, and F. Illas, Phys. Rev. B 67, 115417 (2003).

[54] K. Neyman, C. Inntam, V. Nasluzov, R. Kosarev, and N. Rösch, Appl. Phys. A 78, 823 (2004).

[55] S. Baumann, F. Donati, S. Stepanow, S. Rusponi, W. Paul, S Gangopadhyay, I. G. Rau, G. E. Pacchioni, L. Gragnaniello, M. Pivetta, J. Dreiser, C. Piamonteze, C. P. Lutz, R. M. Macfarlane, B. A. Jones, P. Gambardella, A. J. Heinrich, and H. Brune, Phys. Rev. Lett. 115, 237202 (2015).

[56] O. R. Albertini, A. Y. Liu, and B. A. Jones, Phys. Rev. B 91, 214423 (2015).

[57] S. Baumann, Ph.D. thesis, University of Basel, 2015. 